\title{
Stereotactic implantation of deep brain stimulation electrodes: a review of technical systems, methods and emerging tools
}

\author{
Simone Hemm and Karin Wårdell
}

\section{Linköping University Post Print}

N.B.: When citing this work, cite the original article.

The original publication is available at www.springerlink.com:

Simone Hemm and Karin Wårdell, Stereotactic implantation of deep brain stimulation electrodes: a review of technical systems, methods and emerging tools, 2010, Medical and Biological Engineering and Computing, (48), 7, 611-624.

http://dx.doi.org/10.1007/s11517-010-0633-y

Copyright: Springer Verlag (Germany) http://www.springerlink.com/

Postprint available at: Linköping University Electronic Press

http://urn.kb.se/resolve?urn=urn:nbn:se:liu:diva-58056 
Stereotactic implantation of deep brain stimulation electrodes - a review of technical systems, methods and emerging tools

\section{Simone Hemm ${ }^{1}$ and Karin Wårdell ${ }^{2}$}

${ }^{1}$ University of Applied Sciences Northwestern Switzerland

Institute for Medical and Analytical Technologies

${ }^{2}$ Department of Biomedical Engineering

Linköping University, Sweden

\section{Corresponding author}

Karin Wårdell

Department of Biomedical Engineering

Linköping University

58185 Linköping, Sweden

email : karwa@imt.liu.se

phone: +46-13-222455

fax: +46-13-101902

Total number of words of the manuscript: 10029

The number of words of the abstract: 153

The number of figures: 5

The number of tables: 0 


\begin{abstract}
Deep brain stimulation (DBS) has become increasingly important for the treatment and relieve of neurological disorders such as Parkinson's disease, tremor, dystonia and psychiatric illness. As DBS implantations, and any other stereotactic and functional surgical procedure, require accurate, precise and safe targeting of the brain structure, the technical aids for preoperative planning, intervention and postoperative follow up have become increasingly important. The aim of this paper is to give an overview, from a biomedical engineering perspective, of a typical implantation procedure and current supporting techniques. Furthermore emerging technical aids not yet clinically established are presented. This includes the state-of-the-art of patient specific simulation of DBS electric field, optical methods for intracerebral guidance, movement pattern analysis, new stimulation devices and trends related to neuroimaging, visualization and navigation. As DBS surgery already today is an information technology intensive domain an "intuitive visualization" interface for improving management of these data in relation to surgery is suggested.
\end{abstract}

\title{
Key words
}

Stererotactic and functional neurosurgery; deep brain stimulation; neuroimaging; neuronavigation; safety

\section{Glossary of terms}

AC PC anterior and the posterior commissure

DBS deep brain stimulation

DTI diffusion tensor imaging

FEM finite element method

GPi globus pallidus internus

LDPM laser Doppler perfusion monitoring

MER microelectrode recording

PPN pedunculopontine nucleus

RF radiofrequency

SAR specific absorption rate

STN subthalamic nucleus

UPDRS Unified Parkinson's Disease Rating Scale

Vim nucleus ventrointermedius of the thalamus

$\mathrm{Zi} \quad$ zona incerta 


\section{Introduction}

Implantable neurostimulation devices have become increasingly important as tools for the improved treatment of neurological disorders. Technological advances have made it possible for patients suffering from a wide range of neurological symptoms to receive effective relief by means of cochlear implants, cortical and deep brain stimulators, and systems for spinal cord, vagus, and gastric nerve stimulation [94]. Among these techniques deep brain stimulation (DBS) has become one of the most important interventional methods in functional neurosurgery today, and more than 40,000 DBS implant procedures have been performed worldwide [10]. Research on DBS is currently being performed in many clinics, and over 4200 scientific publications (PubMed Jan. 12, 2010) related to DBS have been published, but only very few of them are technical ones.

Other interventional methods used for similar therapeutic purposes are radiofrequency (RF)lesioning [46, 67], targeted drug therapy and neural cell grafting [68]. RF-lesioning is sometimes suggested as an option together with DBS in order to tailor the patient treatment $[15,39]$. Targeted drug therapy and neural cell grafting are procedures assumed to have major potential applications for the future, though it has not yet become established clinically. Thus, DBS implantation is expected to remain the main surgical mode of treatment for Parkinson's disease and related movement disorders for at least the next decade.

As DBS implantations, and any other stereotactic and functional intervention procedure, require accurate, precise and safe targeting of the brain structure for optimal clinical outcome, the technical aids have become increasingly important. The concept of stereotactic and functional neurosurgery has a history back to the $1940^{\text {th }}$ [34] when the first lesioning procedures were commenced due to the development of stereotactic frames and later on the introduction of brain atlases with well defined landmarks. Recent improvements of biomedical imaging and intra-operative measurement techniques have contributed to a fast increase in the number of stereotactic procedures and thus DBS-implantations. The aim of this paper is to give an overview, from a biomedical engineering perspective, of the current technical aids and future trends in stereotactic DBS implantation procedures. 


\section{Target areas and clinical symptoms in deep brain stimulation}

As the target area, often located in the basal ganglia or thalamus, is usually only slightly larger than the DBS-electrode itself (diameter $=1.27 \mathrm{~mm}$ Medtronic Model 3389, while the target diameter ranges from a few $\mathrm{mm}$ to about $1 \mathrm{~cm}$ ), the positioning of the electrode is of utmost importance if an optimal clinical outcome, with minimal side-effects, is to be achieved. The structures deep within the brain that are commonly used as targets for the reduction of motor Parkinsonian manifestations are, for tremor and rigidity, the subthalamic nucleus (STN); for tremor alone, the nucleus ventrointermedius of the thalamus (Vim); and for rigidity, for L-DOPA-induced dyskinesia or for dystonia (characterized by involuntary muscle contractions), the globus pallidus internus (GPi). Depending on the particular motor manifestations that are to be treated, other structures can be targeted as well, such as the zona incerta $(\mathrm{Zi})$ or a thalamic subnucleus. Additional targets for deep brain stimulation are currently the subject of intensive research, and it can thus be expected that further types of neurological disturbances will become treatable with DBS. Examples of newer target areas include the pedunculopontine nucleus (PPN, for Parkinsonian manifestations such as impaired gait and balance) [98] the internal capsule (for obsessive-compulsive disorder) [21] and Brodmann area 25 (for depression) [82]. Other disorders that are under trial for DBS are epilepsy [116], Tourette syndrome [1], cluster headache [74] and schizophrenia [86]. Thus, the future clinical applications of DBS are expected to include stimulation not just in the already identified targets, but also in a wide range of brain structures and nuclei, each target corresponding to a particular clinical manifestation or set of manifestations to be treated or reduced. The concept of DBS is thus expected to go towards a more general concept of "BS" Brain Stimulation.

\section{Surgical implantation and current supporting techniques}

Until now Medtronic Corporation (Minneapolis, MN, USA) provides the only DBS system approved by the FDA for clinical use of Parkinson's disease and related movement disorders. This is expected to change in the future as several companies are known to do research and development in the area. The most commonly used DBS electrodes have four contacts (Medtronic's leads and electrode models 3389 and 3387). The voltage is often set at a value between $1-4 \mathrm{~V}$, the frequency is set between 130-185 Hz, the pulse width is between 60 and $450 \mu$ s and the stimulation mode can be mono- or bipolar. Uni- or bilateral implantation is used depending on symptoms and target areas. The surgical procedure is divided in two steps; the implantation of the DBS electrode and the pulse generator. This paper focuses on the 
DBS-implantation. However, the way in which different clinical centres perform DBS electrode implantations often differs. In general, the procedure can be distinguished according to preoperative planning, surgical procedure and postoperative follow-up [79, 103, 115] (Fig. 1):

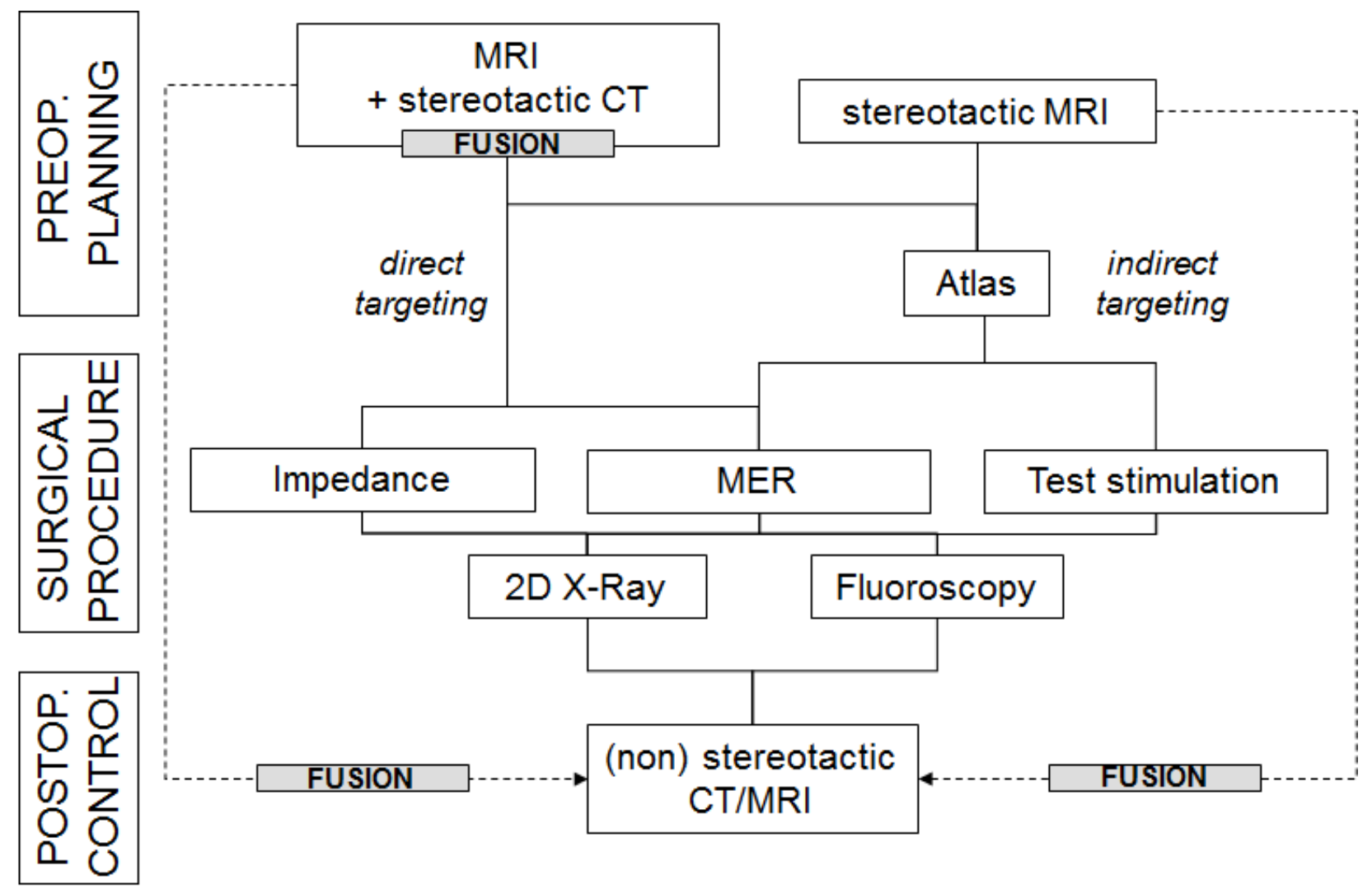

Fig. 1 Current supporting techniques for DBS surgery.

\subsection{Preoperative planning}

The first part is preoperative planning where the specific target in the brain and the trajectory to reach this target are planned on preoperative anatomical images. In general fiducials are affixed to the skull of the patient via a stereotactic system in order to introduce a reference system to the images. Different frameless fiducial systems for DBS implantation have been described and compared with frame based systems [9, 13, 24, 30, 56, 75, 102] but stereotactic frame based systems remain the gold standard. In consequence, this article will concentrate on the procedures using the stereotactic frame. Comparing the implantation procedures in different clinical centres, differences in the preoperative part can especially be found in the stereotactic system, the imaging modality, the moment of image acquisition and the targeting technique.

Concerning the stereotactic systems, differences do exist such as the type of coordinate system used, either a Cartesian coordinate system with $\mathrm{x}, \mathrm{y}$ and $\mathrm{z}$ coordinates ( $\mathrm{G}$ frame, 
Leksell Stereotactic Systems ${ }^{\circledR}$ )[78] or a polar coordinate system describing the target by angles to horizontal and vertical plane and the distance to a reference point (Cosman-RobertWells CRW frame, Riechert-Mundinger frame)[64]. Furthermore, sometimes a phantom base exists to confirm accuracy of coordinate adjustment and integrity of the entire stereotactic system (CRW, Riechert-Mundinger frame). The coordinate calculation is usually performed with a commercially available stereotactic software: iPlan (BrainLab AG, Munich, Germany), SurgiPlan (Elekta Instrument AB, Stockholm, Sweden), Framelink (Medtronic Incorporation, Minneapolis, MN, USA) and STP (Stereotactic Treatment Planning System; Howmedica Leibinger GmbH, Freiburg, Germany).

Concerning the imaging modalities, ventriculography has historically been the gold standard based on its highly reliable identification of the anterior and the posterior commissure (AC, PC) used as references for atlas-based indirect targeting. Today it has been replaced by CT and MR imaging $[103,115]$. MRI is the imaging modality of choice to visualise the anatomic targets. The sequence used depends on the chosen target structure: $\mathrm{T}_{1}$ [22] or proton density imaging [54] is especially used for targeting of the globus pallidus, $\mathrm{T}_{2}$ imaging for STN targeting $[46,103,106]$, inversion recovery images are also beneficial for direct targeting of GPi and STN [99].

Moments of image acquisition can be different. Some centres acquire stereotactic MRI the day of implantation just before surgery [23], while others perform the MRI the day before surgery and reposition the stereotactic frame the day of surgery [73]. More often, an MRI is acquired some days before the implantation to be merged with a stereotactic CT of the day of surgery $[88,110]$.

Furthermore, there are two types of targeting techniques. The planning, i.e. the way the definition of entry point, trajectory and target takes place is sometimes based on MR or, CT and MR data alone [23, 46] which is called "direct targeting". Other groups prefer using anatomical brain atlases created from dissected brains and superimposing them to the MRI ("indirect targeting") to improve the identification of nuclei in the thalamus or basal ganglia (e.g. STN, GPi), or other invisible or hardly identifiable structures of the deep brain. Modern versions of the Schaltenbrandt-Wahren and the Talairach atlases [91] as well as for Morel's atlas [89], a specific stereotactic atlas of the human thalamus and basal ganglia, are available for computer use and as 3D image reconstructions. Another approach to perform an accurate 3D multiplane analysis is manual segmentation with the help of stereotactic books and 4.7 Tesla MRI anatomy software [73]. 


\subsection{Surgical procedure}

The second part of the procedure is the intervention itself. It can be performed under local or general anaesthesia depending on if the patient's feedback is needed for specific testing or not. In the first case supplementary techniques are used to get additional information about the target area, in the latter the DBS electrode is directly implanted at the target chosen during the preoperative planning phase.

For a number of reasons, including individual variability regarding brain anatomy, several problems may arise during a DBS implantation. One of these is the "brain shift" that occurs in conjunction with trepanation. It can cause a deviation from the pre-planned target coordinates resulting in suboptimal anatomical location with side disorders or with haemorrhage if the stereotactic probe injures a blood vessel $[44,62]$. This is one of the reasons in addition to the varying brain anatomy why intraoperative measurements are often performed. Such complementary intraoperative data acquisition methods can be for example impedance measurements while creating the trajectory for the DBS electrode, giving an idea of the surrounding structures passed [66, 123]. Another often used method is microelectrode recording (MER) which is based on registering neuronal activity [26, 40]. Registration is recorded along one to five trajectories in the volume of interest to identify the different structure boundaries. In general, these measurements are performed in millimetre steps before reaching the target and often measurements even go beyond the target structure. Most centres using microelectrode recording perform, as well, intraoperative stimulation along the trajectory using the microelectrodes stimulating in the microampere range $[24,32,110]$ or macroelectrodes stimulating in the milliampere range for example using RF- or DBS stimulation electrodes $[13,88,106]$. In general this is done at the same measurement points as for MER, to evaluate the clinical effects with increasing stimulation voltage and to determine symptom reduction, the clinical therapeutic and side effect thresholds at each measurement point.

The interpretation of all the intraoperative data in order to take a decision on the final surgical target is in general done by the neurosurgeon or neurologist by "mental imagination" i.e. interpreting mentally and combining the anatomic position of each measurement value with the results of MER and test stimulation including clinical efficacy, therapeutic stimulation threshold, side effects and stimulation range. During the surgery some groups perform an intraoperative position control in order to check the absence of deviation of the electrode from 
the planned trajectory. Some groups do compensation due to their experience. This can be an intraoperative 2D X-Ray control [23, 26, 104].

\section{$\underline{3.3 \text { Postoperative follow-up }}$}

Postoperatively, a control of the final electrode position and the absence of haemorrhage via CT or MRI [50, 100, 106] is commonly part of the protocol (Fig. 2). This is then done directly after the implantation procedure with or without the frame on. Due to the electrode artefacts on the postoperative images hiding parts of the anatomical structures, pre- and postoperative images are often merged using stereotactic planning software - sometimes as well with anatomical atlases - in order to be able to identify the anatomical structures around each electrode contact. Furthermore, this image fusion is part of a quality control as it makes possible a comparison between the planned and the final electrode position.
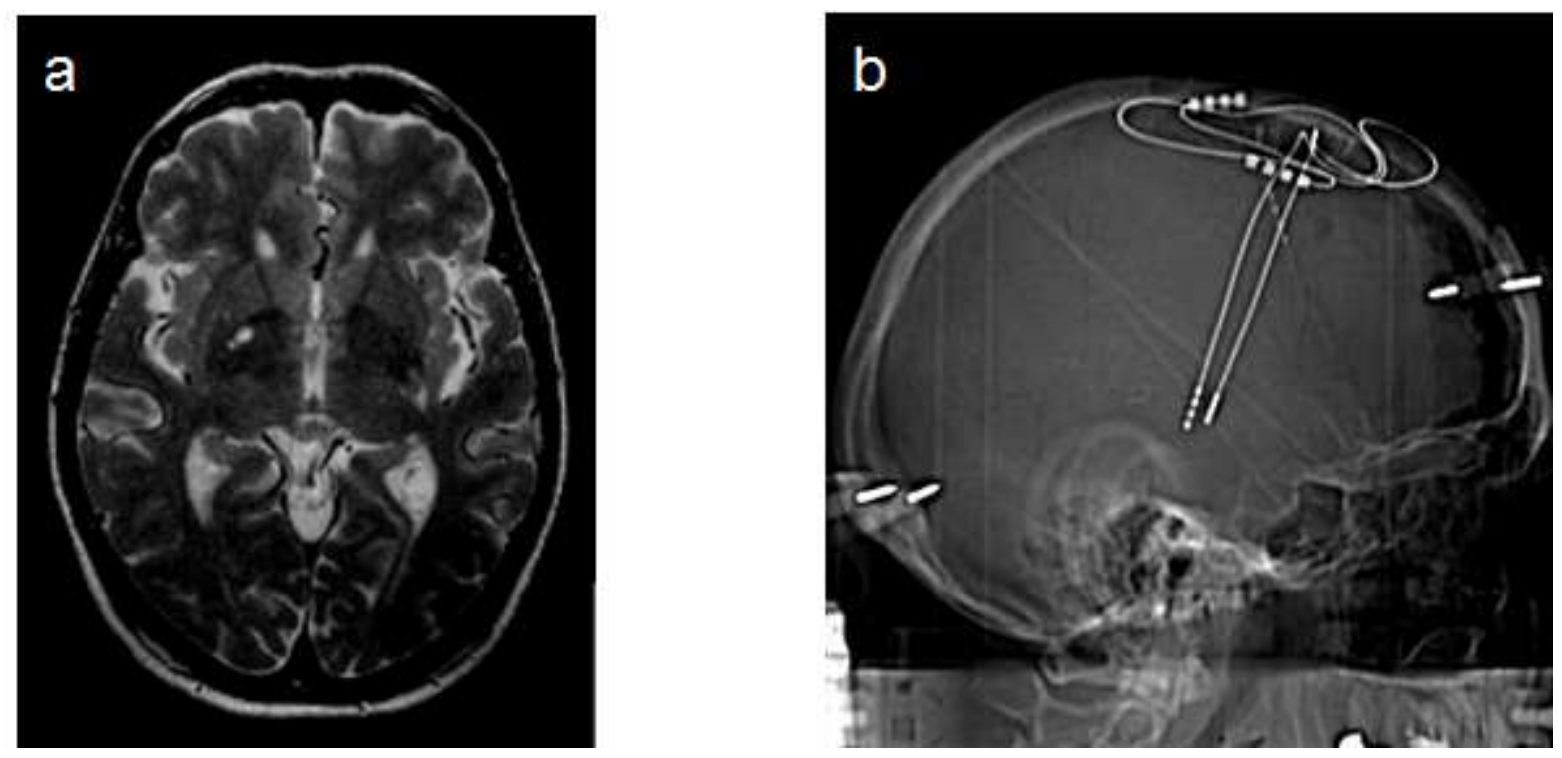

Fig. 2 a T2 weighted 1.5 T MR image used for planning and b CT image with implanted electrodes in Vim and STN.

The patient follow-up is as well part of the postoperative follow-up, it consists of regular consultations. Especially at the early stage, stimulation parameters have to be adapted individually: stimulated contacts, pulse width, frequency and voltage have to be programmed. When an ON/OFF effect (immediate disappearance and reappearance respectively of symptoms) exists, as is the case for tremor, many centres perform a test session where all the four electrode contacts are successively activated with increasing voltage to identify firstly the therapeutically effective contacts. Furthermore the "symptom arrest threshold", i.e. the lowest voltage for which symptoms disappear, and the "side effect threshold", i.e. the lowest voltage 
for which side effects start to occur [26] can be determined. When the therapeutic effect is not immediate and may take days to several months, as for dystonia, a long lasting test period is needed in searching for the optimal stimulation parameters. In these cases, the choice of the first parameter configuration is based on experience and can be guided by the anatomic contact position especially when postoperative MRI could be performed [23, 26].

\section{Emerging techniques and future trends}

Already today, DBS surgery is a technology intensive domain. A high quantity of data is recorded before, during and after the intervention. Information technology is the key to improving management and visualizations of these data, and to implement new supporting technologies in order to optimize the trajectory planning and final stimulation target choice. Examples of emerging tools with great potential but still not established in clinical routine are patient specific electric field modeling and simulation, optical intracerebral measurements and quantitative indicators for intraoperative surgical planning and postoperative surgical outcome investigation of e.g. movement pattern. Furthermore new stimulation systems and improved biomedical imaging technologies will play a significant future role. The "mental imagination" of neurosurgeons during surgery of the optimal stimulation target, based on anatomy and on the intraoperative measurements, is expected to be replaced by user-friendly visualizing tools facilitating final target choice, "intuitive visualization”. Emerging techniques, not yet clinical routine, are briefly presented below.

\subsection{Patient specific modeling and simulation of the DBS electric field}

The finite element method (FEM) has been used in order to develop computer-models of DBS-electrodes and to create simulations of the electric field surrounding DBS-electrodes [4, $51,83,122]$ The first generation of DBS-models were used to visualize the electric field for different stimulation settings (monopolar and bipolar) and with reference to the pre-selected stereotactic target area and anatomy e.g. the GPi [51] and the STN [83]. Other studies focused on the influence from tissue type in the vicinity of the stimulation area e.g. cerebrospinal filled cysts [4] or the electrode-brain interface [121]. McIntyre and colleagues [83] also used FEM simulations together with an axon model in order to study the axonal tissue around the STN directly activated by DBS.

The second generation of modeling techniques is patient and treatment specific i.e. based on individual input data and electrode settings [7, 17, 112]. Butson and co-workers were, by using diffusion tensor imaging (DTI) as input for handling potential anisotropic tissue 
(variation in electrical conductivity) able to in detail study the electric potential when stimulating in the STN [17]. The technique has been further developed and used in ten patients in order to identify and visualize the theoretical volume of activated tissue around the STN [80]. The activated volume around the GPi has been studied and visualized with a computational stereotactic model by Vasques and colleagues [112]. An approach based on the individual patient's preoperative MR batch of images in order to classify the electrical conductivity for different tissue types has been developed by Åström et al., [7]. With the help of treatment-specific positioning of the DBS electrode in relation to the postoperative MR images, the method allows for investigations of the relative electric field changes in relation to anatomy and DBS-settings (Fig. 3). The latter technique has been used for evaluation of speech intelligibility and movement in ten patients with Parkinson's disease where DBS electrodes were implanted in the STN [5].
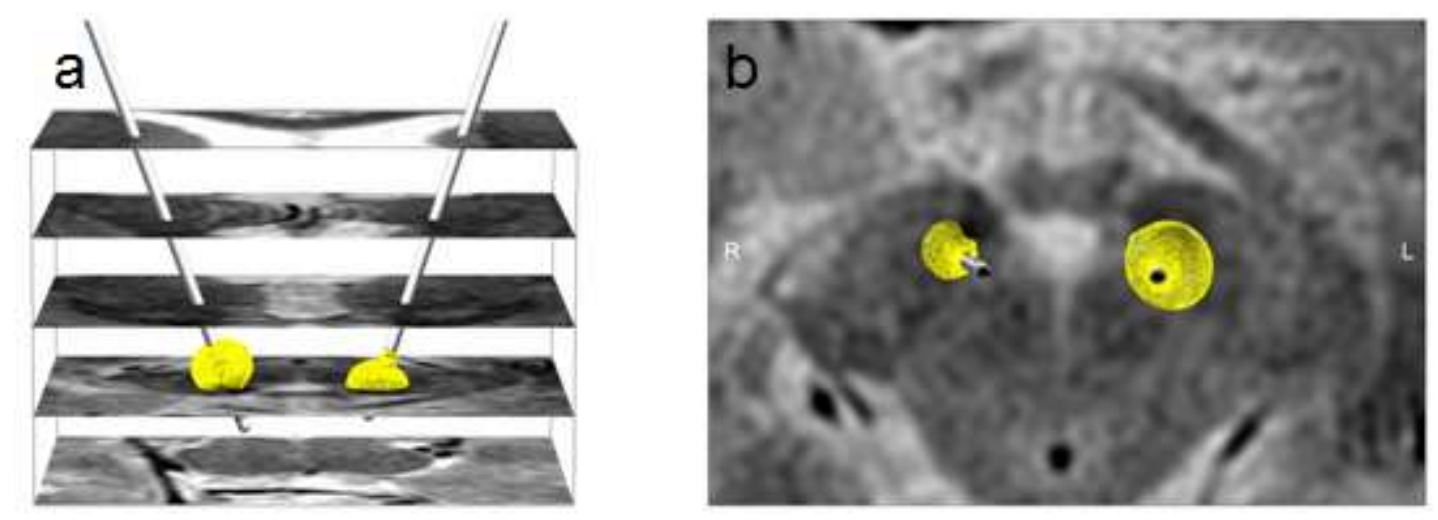

Fig. 3 Patient specific simulation of bilateral DBS in the STN during clinically effective stimulation settings. a The electric field is visualized with isosurfaces at $0.2 \mathrm{~V} / \mathrm{mm}$. b Axial model slice visualizing the electric field isolevel at $0.2 \mathrm{~V} / \mathrm{mm}$ together with the anatomy.

\subsection{Optical intracerebral measurements}

Optical intracerebral measurement is a technique for real-time presentation of grey-white tissue boundaries during stereotactic procedures. Reflectance spectroscopy measurements in the near infrared region have been performed by several investigators in order to discriminate between white and grey brain matter during both experimental and clinical stereotactic neurosurgery $[3,36]$. Up to date, the spectral measurements during clinical implantations of DBS electrodes have been used by Giller and co-workers in more than 200 implantation procedures and also been compared with microelectrode recording [35]. The concept developed by Wårdell and colleagues, which is based on both laser Doppler perfusion monitoring (LDPM) [118] and diffuse reflection spectroscopy [2], have been clinically 
evaluated on more than 50 DBS lead implantations and compared to impedance recordings [58]. This group extracts curve data from specific wavelength intervals e.g. around 573 (blood content) and $780 \mathrm{~nm}$ (grey-white boundaries), the latter wavelength also applicable in the LDPM system, whereas Giller and co-workers are using the tilt of the curve within an interval in the rear infrared region. Despite slightly different signal processing, both research groups present similar optical signatures along trajectories towards the STN and the thalamus. In general all time-curves start with a low intensity value in cortex and increases to a maximum intensity value when passing the subcortical white matter. The last section differs depending on the target area aimed at. For the GPi a characteristic "double peak", representing light intensity changes during insertion through the white lamina surrounding the Putamen, GPe and GPi has been identified [58] (Fig. 4). This is possible due to the fact that white matter is more opaque than grey matter, and thus the white matter lamina in grey matter is easier to detect than grey matter nuclei in white matter.
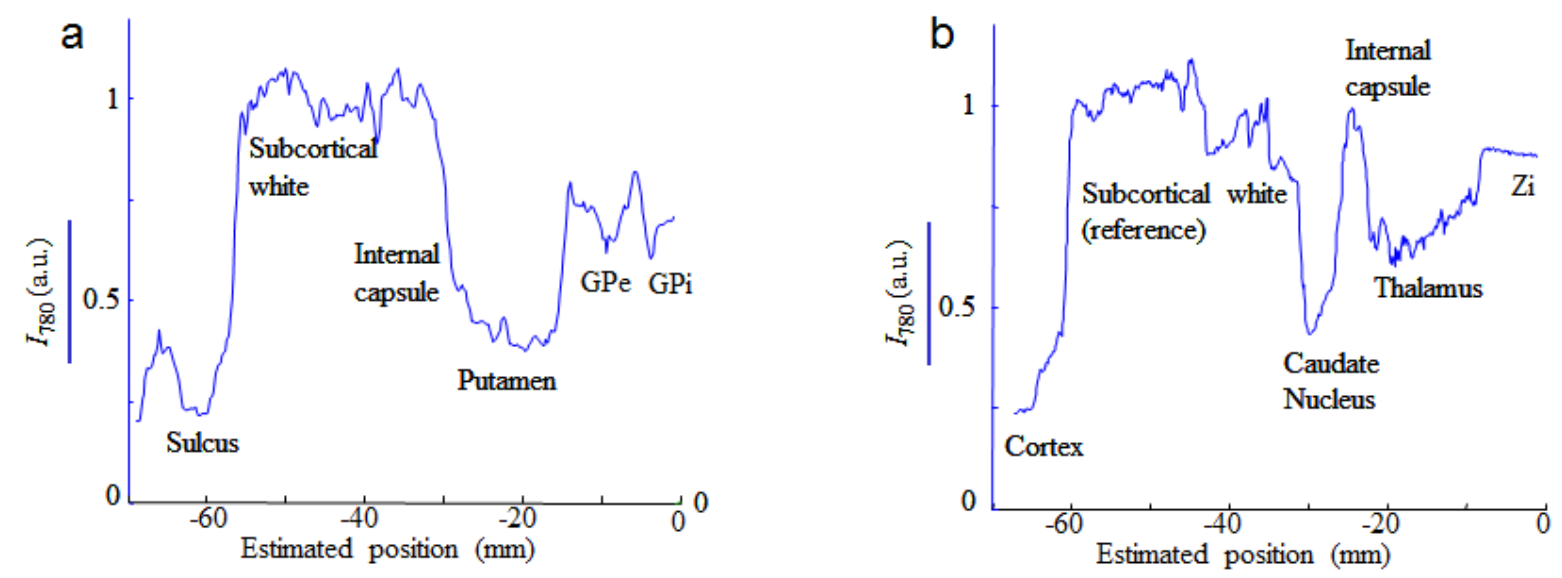

Fig. 4 Continuous light intensity measurements from cortex along the pre-calculated trajectory towards the target area. a GPi and $\mathbf{b} \mathrm{Zi}$. The optical signals are processed for presentation at the wavelength $780 \mathrm{~nm}$. The intensity values represent the changes in tissue grey-whiteness during insertion of the probe.

In general, the light interaction with tissue, and thus the measurement depth, is affected by several aspects such as probe design, light source and the tissue's scattering and absorption characteristics. Experimental investigations and Monte Carlo simulations show that the optical sampling depth in brain tissue is less than $1 \mathrm{~mm}[59,71,101]$. Qian and colleagues [101] studied the "look ahead distance" in brain matter by means of Monte Carlo simulation and found that in the near infrared region and for small fiber separation, grey matter is expected to have a slightly increased "look ahead distance" than white matter. This was confirmed by Johansson et al. [59]. Nevertheless, the optical resolution is higher than the resolution in a 1.5 Tesla MRI system where imaging is done with $2 \mathrm{~mm}$ trans-axial slices. 


\subsection{Movement pattern analysis}

In order to make intraoperative analysis of Parkinson's disease symptoms (tremor, bradykinesia, rigidity, postural instability) and dyskinesia more objective, many centres have introduced movement pattern analysis to their surgical procedure. It exist a variety of laboratory-based systems to quantitatively measure and analyse body movement. This includes systems for movement analysis of dystonia [72], tremor [11, 33, 95], bradykinesia $[29,65]$, gait $[8,48,61]$ and levodopa induced dyskinesias $[37,55]$.

A majority of the mentioned papers deal with the quantitative evaluation of Parkinsonian symptoms in general. Still, only some of the mentioned movement analysis studies for Parkinson's disease have been performed in relation with DBS. Just to name some of them: Kumru [65] examined the effects of STN-DBS on characteristics of EMG activity of the wrist representative for bradykinesia and akinesia of the agonist muscle; Herzog [52] and Fukuda [33] applied accelerometry to compare between results of thalamic and subthalamic nucleus DBS and to correlate PET imaging (regional cerebral blood flow) with tremor in patients with unilateral ventral intermediate (Vim) thalamic nucleus DBS respectively. Sturman [109] examined the efficacy of STN DBS and medication for resting tremor with accelerometery and EMG, Blahak [14] and Timmermann [110] did the same using an ultrasound-based measuring system (Blahak in addition to EMG). Several studies used quantified gait analysis to demonstrate the impact of STN and GPi stimulation on gait and balance [8].

Most of these studies concern pre-/postoperative or stimulation ON/OFF evaluations that means during preoperative office visits, hospitalization for surgery, or postoperative followup visits. Intraoperative quantitative measurement of the motor manifestations of Parkinson's disease has rarely been proposed. Some groups intraoperatively used accelerometry and/or surface EMG [12, 60], accelerometer-based tremor pens and touch recording plates [96], or gyroscopes [63] to try to objectify the assessment of tremor and bradykinesia. Birdno et al [12] used intraoperative accelerometry to demonstrate the influence of the periodicity of DBS on tremor, but did apparently not make it a part of their routine surgical protocol. Journee et al. [60] intraoperatively placed two 1D accelerometers on the index finger and analysed amplitude and frequency as tremor parameters. Even if there is no gold standard today for movement pattern analysis, accelerometers seem to be the most frequently used evaluation technique, but this can as well be linked to the fact that tremor is the mostly evaluated Parkinson's disease symptom. 


\subsection{New stimulation systems}

The last 20 years the market has been dominated by the Medtronic DBS-system which was first approved for clinical use in 1997 [20]. At the moment, several companies and research groups show strong interest in development and improvement of neurostimulation devices [94]. Among these, St. Jude Medical has received the European CE mark approval of the Libra $^{\circledR}$ and LibraX $P^{\mathrm{TM}}$ deep brain stimulation systems for treating symptoms of Parkinson's disease and the first clinical implantations was done in Europe in 2009 [108]. The device is also approved for Investigational Device Exemption from the FDA to evaluate the efficacy of DBS for the treatment of chronic depression by stimulation in Brodmann Area 25. Further development of established electrode techniques are also expected and suggested improvements include: miniaturized cranial implantable neurostimulators which would allow the entire surgical procedure to be done as one incision procedure; material and leads that make MR-imaging safer and reduces the risk of RF-induced heating; and field steering [20]. Steering of the electric field towards a target area of interest has also been simulated. Åström and colleagues [6] used patient specific models and simulations of the electric field to visualize a multi-contact asymmetrical voltage steering techniques beneficial for reduction of DBS induced speech deficits, and Butson and McIntyre [18] evaluated the use of current steering for better control of the activated tissue volume during STN-DBS. Other suggestions to improve the stimulation effect include alteration of the stimulation pulses by desynchronization [49].

\subsection{Neuroimaging, visualization and navigation}

During the last decade, biomedical imaging has gained more and more importance for surgical planning of deep brain stimulation surgery. With the introduction of 3T MR scanners it has become possible to further increase the image quality and resolution [111]. Nevertheless, the choice of the imaging sequence still remains essential to visualise the different targets as illustrated in section 3 of this article.

In order to provide real-time image guidance, interventional MRI has recently been used in some centres performing DBS surgery. One approach is to use an open MRI but due to low image quality of $0.2 \mathrm{~T}$ MRI scans which are sub-optimal for anatomical localization, image fusion with pre-operative higher quality scan is necessary [25]. Another approach is reported by Starr and colleagues $[69,81,107]$. They use a skull-mounted aiming device, the NeXframe 
system, in a standard configuration 1.5 T MR imaging unit, where also the entire surgical procedure is accomplished. In this way surgical planning, guided implantation and final electrode position check is performed intraoperatively. Other alternatives to the traditional frames are the Eljamel-Tulley stereotactic cube [30] and the STarFix ${ }^{\mathrm{TM}}$ microtargeting ${ }^{\mathrm{TM}}$ Platform $[9,24]$. The STarFix ${ }^{\mathrm{TM}}$ platform uses titanium anchors which are implanted into the patient's skull before imaging. Based on the results from high resolution preoperative CT and MR images, a patient and treatment specific platform is constructed. During surgery the platform is mounted on the anchors together with a guide tube which is used for insertion of the DBS-electrode.

Concerning postoperative MR scanning there has been a considerable debate about the safety in patients with DBS systems. Following manufacturer guidelines [85] imaging is possible only with a 1.5 Tesla horizontal bore MRI, a transmit/receive head coil and when limiting the average head specific absorption rate (SAR) to $0.1 \mathrm{~W} / \mathrm{kg}$ or less even if this implicates a lower imaging quality. Otherwise heating, magnetic field interactions or induced stimulation for example can be the consequence [103]. Experiences from MRI of implanted deep brain stimulators on a large patient material have been presented by Larson and colleagues [70].

Diffusion tensor imaging represents another possibility to obtain data using MRI. It is used to measure the water diffusion in multiple directions, which has been proposed to represent the electrical conductivity of the tissue and can be used to visualize nerve bundles in the brain. For the moment, DTI is still in the state of evaluation, i.e. images are acquired preoperatively to deep brain stimulation and they are analysed postoperatively concerning target position and interstructure connections $[43,92,105]$.

Transcranial sonography has started to be applied for the placement of DBS electrodes in dystonic [117] and Parkinsonian patients [90]. Transcranial sonography can display echogenic deep brain structures such as the GPi in dystonic patients and the substantia nigra. Also the STN has been identified considering its topographic relationship with the substantia nigra [90]. For the moment, highly echogenic imaging artefacts of the metal parts of the electrode do exist.

In section 3.2 we show the quantity of existing data that has to be analyzed intraoperatively in order to take a decision on the final surgical target. Most of the clinical groups base their decision on taken notes and the "mental combination" of all these data. None of the existing navigation and planning systems currently proposes an intraoperative "intuitive visualisation" 
interface. The StimPilot Software (Medtronic Inc., Minneapolis, MN) [53] allowed a combined visualisation of short MER recordings together with the anatomical information but it is only commercialised in the US. Only few groups use homemade software for online data collection and visualisation [24, 41, 77]. Most of them use electrophysiological databases of several patients taking into account MER and rarely as well test stimulation results which are non-rigidly registered to the patient's MRI in order to predict preoperative target points. Miocinovic et al [87] have added a feature predicting the volume of tissue activated for a given electrode position and stimulation parameter setting. We are currently setting up a prototype for an interface that will support the management and visualisation of all data achieved during planning and surgery, including new emerging technologies. An example is presented in Fig. 5.

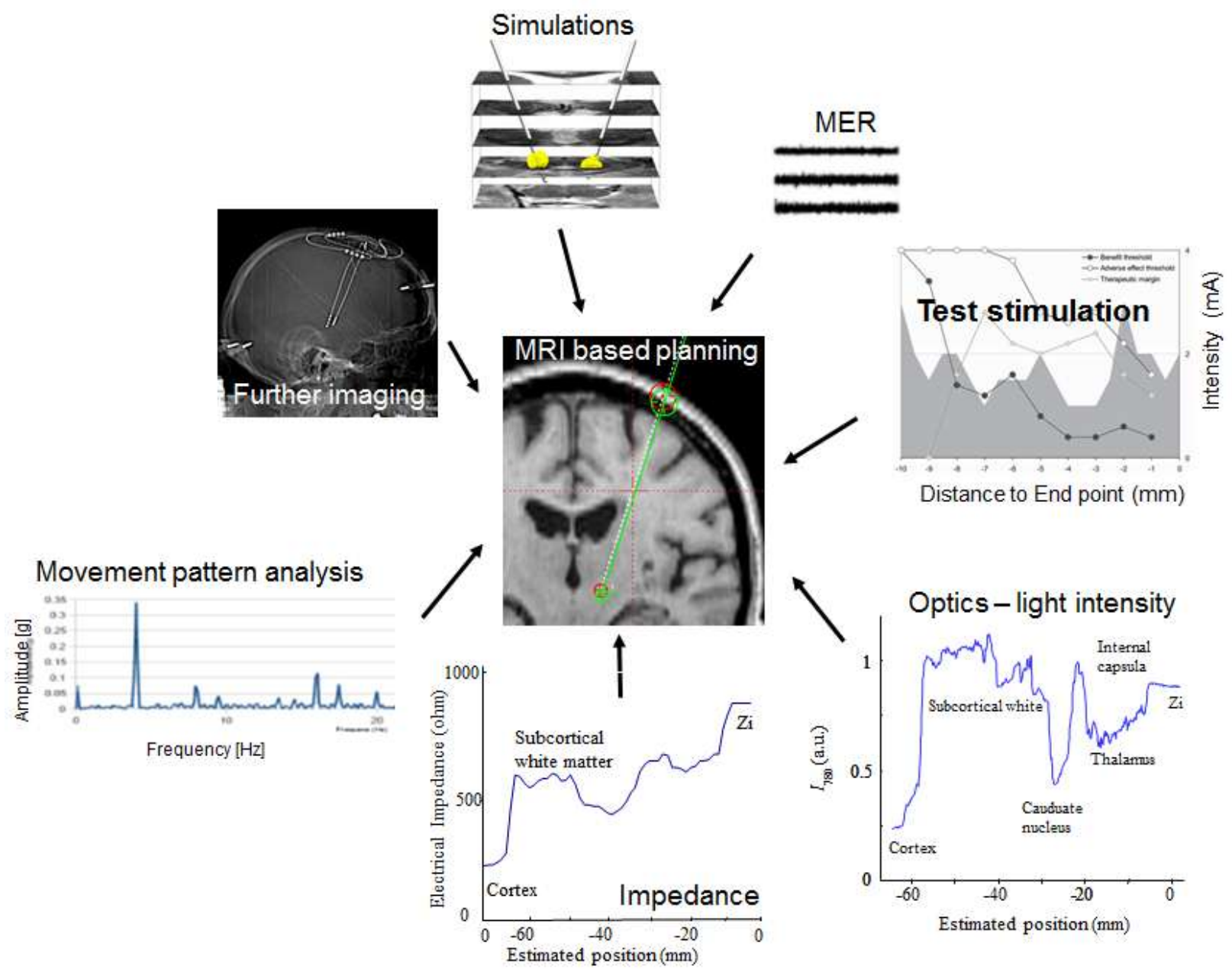

Fig. 5 From "mental imagination" to "intuitive visualization". 


\section{Discussion and Conclusions}

A review of the state-of-the art of technical aids for the stereotactic implantation procedure of deep brain stimulation electrodes has been presented. The preoperative planning, surgical intervention and postoperative follow-up of DBS electrodes include many steps and use a range of information related technologies. A procedure is normally a full day surgery and this makes it both time- and resource consuming. As the number of clinical indications and target areas are expected to increase and thus the number of implantation procedures, it is of outmost importance to make the different steps as effective as possible, but without increasing the surgical risks and jeopardize the final clinical outcome. For any stereotactic procedure, safe, accurate and precise targeting of the brain structure to be treated is essential for an optimal clinical outcome with minimal side disorders.

In order to judge the implantation precision it is important to be aware of precision limits and error risks of the whole surgical procedure from the planning to the postoperative follow-up.

In general it is possible to distinguish between imprecision due to the target identification on the anatomical images (planning procedure) and the imprecision due to the surgery itself. The former one includes first of all the stereotactic image acquisition. Image resolution is dependant on the acquisition parameters. While stereotactic CT acquisitions do not show any geometrical distortion due to the presence of the stereotactic frame, distortions of MR-images and the fiducials can not completely be excluded due to the chemical shift from substances used in the frame localizer system or magnetic susceptibility artifacts due to ferromagnetic materials. Nevertheless, thanks to the MRI-compatible stereotactic systems, several studies could show the absence of significant distortions and the precision of implantation procedures based on stereotactic MRI $[16,114]$, but this is MR-sequence dependant. To avoid distortion and to increase spatial information, many centers use MRI coregistered to CT for the preoperative planning. Occurring errors depend on the image fusion algorithm but seem to remain in acceptable limits [103, 115], for example of around $1.3 \mathrm{~mm}$ for an image fusion based on mutual information [28]. On the contrary to such a rigid intrapatient fusion, it is well known that non-rigid atlas fusion to the patient's MRI introduces uncertainties $[42,113]$ as the atlases do not take into account the discrete anatomical variations among individuals. Especially in the case of GPi and STN targeting, the direct method seems to have obvious benefits over indirect atlas-based targeting [79, 97, 115]. Another important step is the identification of the stereotactic frame by specific software which is the basis for the following target calculation. Depending on how many slices are included in the calculation of 
the transformation parameters, the result can slightly differ. Furthermore, this part is in general semi-automatic as it requires the interaction of the user to indicate or confirm the different fiducial points. Concerning imprecision due to the surgical intervention, there is probably first of all the application accuracy of the frame systems themselves which has been estimated for the different probe positions by Zylka et al. [124]. They took into account imaging accuracy and mechanical errors such as the positioning of the target which depends on the resolution of the different coordinates and the electrode depth. Frame systems with a phantom base allow compensating for mechanical inaccuracies and errors; some centers using frame systems without such a phantom correct the final targets based on their experience with their specific frame. Another phenomenon introducing an inaccuracy whose importance is difficult to predict is the "brain shift". The only way to reduce the causing air entry is to keep the burr hole as small as possible and to perform the surgery as fast as possible [57]. Other sources of surgical inaccuracies can be for example a deviation from the planned trajectory.

The paper has also reviewed a number of emerging tools, several of them being research prototypes today but with great potential to become available in the health care system in the near future. Among these, further development of established brain stimulation electrodes and new stimulation devices developed for specific treatments are expected to push the use of DBS. Miniaturized cranial implantable pulse generators are suggested in order to make the entire surgical procedure as one incision [20] and steering of the electric field for tailoring the treatment and reduce potential side disorders $[6,18]$. However, even with such improvements, the implantation procedure of DBS electrodes will still require stereotactic surgery and support from technical aids. Furthermore imaging quality related to MRI and DTI is expected to improve and may in the future make "invisible" structures possible to visualize. Transcranial sonography may become as well an interesting and promising complementary monitoring technique if the highly echogenic imaging artefacts of the metal parts of the electrode can be reduced. It may allow further intraoperative refinement of the electrode position as well as simultaneous prevention of haemorrhages.

Despite this, the "brain shift" will still be an obstacle to overcome and intraoperative measurements will therefore still be required. To date, microelectrode recording is the most commonly used technique for intracerebal identification of the DBS target areas. Being well established, MER is however sometimes questioned, and some researchers point out that the thin needles used may increase the risk of bleeding and does not guarantee proper targeting 
[45, 93]. Furthermore, MER can be relatively time consuming and as the signals are in general studied in the time domain they may be difficult to interpret in real-time. Optical measurements $[35,58,118]$ are a highly interesting alternative to MER. It has the advantage of real-time presentation of grey-white boundaries passed during probe insertion. A recording is done within minutes. In addition to grey-white boundary determination, vessels in the vicinity to, and along the trajectory, can be detected by means of simultaneous microvascular recordings with laser Doppler technique [119]. By using a multipurpose probe the optical measurements can be combined with impedance recordings [58]. The optical alternative to MER could be especially beneficial for newer target areas were well defined grey-white matter boundaries are passed as the tissue is "seen" before it is reached.

An additional promising tool for exploring new target areas is the use of patient specific models and simulations of the electric field [7, 17]. These can also be used to advance and optimise the treatment of an individual patient and act as a tool for training and for simulation of electrical field in target areas before the actual surgical procedure is done. Such simulations can allow for 3D visualizations of the electric field influenced by the stimulation and match it to the patient's clinical outcome $[5,80]$. As DBS has become more commonly used, there have been increasing reports of postoperative neuropsychiatric complications, including depression, mania, aggression, and language disturbances [19, 47, 120]. Even though several hypothesis of the fundamental mechanisms exist underlying both the therapeutic effects and the adverse side effects of DBS, the mechanism remains largely unknown $[27,38,76,84]$.

In a broader context simulations can, together with e.g. neuroimaging, biochemical monitoring and neuronal mapping be one additional corner stone for increased knowledge of the DBS mechanisms. Another important and self-evident basis of the analysis of the mechanism of action of DBS is the obtained clinical result. Here appears the problem of the comparability of the evaluations performed by different medical doctors and in different medical centres. For Parkinson patients for example it is crucial to assess the severity of the cardinal Parkinson disease symptoms (tremor, bradykinesia, rigidity, postural instability) and dyskinesia to document the clinical changes quantitatively. Current methods such as the Unified Parkinson's Disease Rating Scale (UPDRS) [31] are mainly semi-quantitative and not fully objective: these clinical scales rely on ordinal ratings based on descriptive terms such as "mild," "moderate," and "severe". The literature review has shown that many groups have worked on quantitative movement pattern analysis, but that there is no gold standard and no 
complete pre- and postoperative evaluation of all Parkinson's disease symptoms. This is valid as well for the intraoperative evaluation process. Only few groups have tried to introduce quantitative measurement methods in the operating theatre which could further increase the precision of the target choice. For other disorders treated with DBS, such as psychiatric illness, techniques in parallel to movement pattern monitoring should be developed in order to optimize the objectivity of the clinical evaluation.

Another key point which could improve the surgical decision-making process would be to introduce data and information technologies in the DBS procedure i.e. by means of "intuitive visualization" of parameters and images recorded in relation to the intervention. As already mentioned, existing homemade and commercialized software provides in general an integration of microelectrode recordings with the patients MR images and sometimes as well with the test stimulation results. An extended system for visualization of additional parameters could include presentation of the patient MR batch of images together with the DBS electric field simulation or physiological information such as tissue impedance, neural activity recorded by MER, grey-white boundaries, microvascular perfusion related to small vessel structures or tissue chromophores measured by optics. Furthermore, depending on clinical symptoms for the implantation procedure, movement pattern could be included. In consequence there still seems to be a high potential to optimise the surgery and its precision by means of objectification and improved data management for patients suffering from various movement disorders or other diseases treated by deep brain stimulation.

\section{Acknowledgements}

This work was supported by the Swedish Foundation for Strategic Research (SSF), Swedish Research Council (VR) and Swedish Governmental Agency for Innovation Systems (VINNOVA grant 311-2006-7661). Financial support has been obtained as well from the Förderverein Solothurn of the University of Applied Sciences Northwestern Switzerland. 


\section{References}

1. Ackermans L, Temel Y, Visser-Vandewalle V (2008) Deep brain stimulation in Tourette's Syndrome. Neurotherapeutics 5(2):339-44

2. Antonsson J, Eriksson O, Blomstedt P, Bergenheim AT, M IH, Richter J, Zsigmond P, Wårdell K (2008) Diffuse reflectance spectroscopy measurements for tissue-type discrimination during deep brain stimulation. J Neural Eng 5(2):185-90

3. Antonsson J, Eriksson O, Wardell K. (2003) In-vivo reflection spectroscopy measurements in pig brain during stereotactic surgery. Advanced Biomedical and Clinical Diagnostic Systems. 1 ed. SPIE, San Jose, CA, USA, pp 242-250

4. Åström M, Johansson JD, Hariz MI, Eriksson O, Wårdell K (2006) The effect of cystic cavities on deep brain stimulation in the basal ganglia: a simulation-based study. $\mathrm{J}$ Neural Eng 3(2):132-8

5. Åström M, Tripoliti E, Hariz IM, Zrinzo LU, Matinez-Torres I, Limousin P, Wårdell K (2010) Patient-specific model-based investigation of speech intelligibility and movement during deep brain stimulation. Submitted

6. Åström M, Tripoliti E, Zrinzo L, Martinez-Torres I, Limousin P, Hariz M, Wårdell K (2008) Voltage steering to control deep brain stimulation-induced speech deficits. Acta Neurochirurgica 150:953-54 abstract

7. Åström M, Zrinzo LU, Tisch S, Tripoliti E, Hariz MI, Wårdell K (2009) Method for patient-specific finite element modeling and simulation of deep brain stimulation. Med Biol Eng Comput 47(1):21-8

8. Bakker M, Esselink RA, Munneke M, Limousin-Dowsey P, Speelman HD, Bloem BR (2004) Effects of stereotactic neurosurgery on postural instability and gait in Parkinson's disease. Mov Disord 19(9):1092-9

9. Balachandran R, Mitchell JE, Dawant BM, Fitzpatrick JM (2009) Accuracy evaluation of microTargeting Platforms for deep-brain stimulation using virtual targets. IEEE Trans Biomed Eng 56(1):37-44

10. Benabid AL, Chabardes S, Mitrofanis J, Pollak P (2009) Deep brain stimulation of the subthalamic nucleus for the treatment of Parkinson's disease. Lancet Neurol 8(1):67-81

11. Beuter A, Edwards R (2002) Kinetic tremor during tracking movements in patients with Parkinson's disease. Parkinsonism Relat Disord 8(5):361-8

12. Birdno MJ, Kuncel AM, Dorval AD, Turner DA, Grill WM (2008) Tremor varies as a function of the temporal regularity of deep brain stimulation. Neuroreport 19(5):599-602

13. Bjartmarz H, Rehncrona S (2007) Comparison of accuracy and precision between frame-based and frameless stereotactic navigation for deep brain stimulation electrode implantation. Stereotact Funct Neurosurg 85(5):235-42

14. Blahak C, Wohrle JC, Capelle HH, Bazner H, Grips E, Weigel R, Hennerici MG, Krauss JK (2007) Tremor reduction by subthalamic nucleus stimulation and medication in advanced Parkinson's disease. J Neurol 254(2):169-78

15. Blomstedt P, Hariz GM, Hariz MI (2006) Pallidotomy versus pallidal stimulation. Parkinsonism Relat Disord 12(5):296-301

16. Burchiel KJ, Nguyen TT, Coombs BD, Szumoski J (1996) MRI distortion and stereotactic neurosurgery using the Cosman-Roberts-Wells and Leksell frames. Stereotact Funct Neurosurg 66(1-3):123-36

17. Butson CR, Cooper SE, Henderson JM, McIntyre CC (2007) Patient-specific analysis of the volume of tissue activated during deep brain stimulation. Neuroimage 34(2):661-70

18. Butson CR, McIntyre CC (2008) Current Steering to Control the Volume of Tissue Activated During Deep Brain Stimulation. Brain Stimulat 1(1):7-15 
19. Castner JE, Copland DA, Silburn PA, Coyne TJ, Sinclair F, Chenery HJ (2008)

Subthalamic stimulation affects homophone meaning generation in Parkinson's disease. J Int Neuropsychol Soc 14(5):890-4

20. Coffey RJ (2009) Deep brain stimulation devices: a brief technical history and review. Artif Organs 33(3):208-20

21. Cosyns P, Gabriels L, Nuttin B (2003) Deep brain stimulation in treatment refractory obsessive compulsive disorder. Verh K Acad Geneeskd Belg 65(6):385-99; discussion 399-400

22. Coubes P, Roubertie A, Vayssiere N, Hemm S, Echenne B (2000) Treatment of DYT1generalised dystonia by stimulation of the internal globus pallidus. Lancet 355(9222):2220-1

23. Coubes P, Vayssiere N, El Fertit H, Hemm S, Cif L, Kienlen J, Bonafe A, Frerebeau P (2002) Deep brain stimulation for dystonia. Surgical technique. Stereotact Funct Neurosurg 78(3-4):183-91

24. D'Haese PF, Cetinkaya E, Konrad PE, Kao C, Dawant BM (2005) Computer-aided placement of deep brain stimulators: from planning to intraoperative guidance. IEEE Trans Med Imaging 24(11):1469-78

25. De Salles AA, Frighetto L, Behnke E, Sinha S, Tseng L, Torres R, Lee M, CabatanAwang C, Frysinger R (2004) Functional neurosurgery in the MRI environment. Minim Invasive Neurosurg 47(5):284-9

26. Derost PP, Ouchchane L, Morand D, Ulla M, Llorca PM, Barget M, Debilly B, Lemaire JJ, Durif F (2007) Is DBS-STN appropriate to treat severe Parkinson disease in an elderly population? Neurology 68(17):1345-55

27. Dostrovsky JO, Lozano AM (2002) Mechanisms of deep brain stimulation. Mov Disord 17 Suppl 3:S63-8

28. Duffner F, Schiffbauer H, Breit S, Friese S, Freudenstein D (2002) Relevance of image fusion for target point determination in functional neurosurgery. Acta Neurochir (Wien) 144(5):445-51

29. Dunnewold RJ, Jacobi CE, van Hilten JJ (1997) Quantitative assessment of bradykinesia in patients with Parkinson's disease. J Neurosci Methods 74(1):107-12

30. Eljamel MS, Tulley M, Spillane K (2007) A simple stereotactic method for frameless deep brain stimulation. Stereotact Funct Neurosurg 85(1):6-10

31. Fahn S, Elton RL (1987) Unified Parkinson's disease rating scale. In: Fahn S, Marsden CD, Goldstein M (eds). Recent developments in Parkinson's disease. Macmillian, New York, pp 153-163

32. Finnis KW, Starreveld YP, Parrent AG, Sadikot AF, Peters TM (2003) Threedimensional database of subcortical electrophysiology for image-guided stereotactic functional neurosurgery. IEEE Trans Med Imaging 22(1):93-104

33. Fukuda M, Barnes A, Simon ES, Holmes A, Dhawan V, Giladi N, Fodstad H, Ma Y, Eidelberg D (2004) Thalamic stimulation for parkinsonian tremor: correlation between regional cerebral blood flow and physiological tremor characteristics. Neuroimage 21(2):608-15

34. Gildenberg PL, Krause JK (2009) The history of stereotactic and functional neurosurgery. In: Lozano AM, Gildenberg PL, Tasker RR (eds). Textbook of stereotactic and functional neurosurgery. Springer, Vol. 1, pp 3-33

35. Giller CA, Liu H, German DC, Kashyap D, Dewey RB (2009) A stereotactic nearinfrared probe for localization during functional neurosurgical procedures: further experience. J Neurosurg 110(2):263-73

36. Giller CA, Liu HL, Gurnani P, Victor S, Yasdani U, German DC (2003) Validation of a near-infrared probe for detection of thin intracranial white matter structures. J Neurosurg 98:1299-1306 
37. Gour J, Edwards R, Lemieux S, Ghassemi M, Jog M, Duval C (2007) Movement patterns of peak-dose levodopa-induced dyskinesias in patients with Parkinson's disease. Brain Res Bull 74(1-3):66-74

38. Gradinaru V, Mogri M, Thompson KR, Henderson JM, Deisseroth K (2009) Optical deconstruction of parkinsonian neural circuitry. Science 324(5925):354-9

39. Greenberg BD, Rauch SL, Haber SN (2009) Invasive circuitry-based neurotherapeutics: stereotactic ablation and deep brain stimulation for OCD. Neuropsychopharmacology 35(1):317-36

40. Gross RE, Krack P, Rodriguez-Oroz MC, Rezai AR, Benabid AL (2006) Electrophysiological mapping for the implantation of deep brain stimulators for Parkinson's disease and tremor. Mov Disord 21(S14):S259-S283

41. Guo T, Finnis KW, Parrent AG, Peters TM (2006) Visualization and navigation system development and application for stereotactic deep-brain neurosurgeries. Comput Aided Surg 11(5):231-9

42. Guo T, Parrent AG, Peters TM (2007) Surgical targeting accuracy analysis of six methods for subthalamic nucleus deep brain stimulation. Comput Aided Surg 12(6):32534

43. Gutman DA, Holtzheimer PE, Behrens TE, Johansen-Berg H, Mayberg HS (2009) A tractography analysis of two deep brain stimulation white matter targets for depression. Biol Psychiatry 65(4):276-82

44. Halpern CH, Danish SF, Baltuch GH, Jaggi JL (2008) Brain shift during deep brain stimulation surgery for Parkinson's disease. Stereotact Funct Neurosurg 86(1):37-43

45. Hariz MI (2002) Safety and risk of microelectrode recording in surgery for movement disorders. Stereotact Funct Neurosurg 78(3-4):146-57

46. Hariz MI (2003) From functional neurosurgery to "interventional" neurology: survey of publications on thalamotomy, pallidotomy, and deep brain stimulation for Parkinson's disease from 1966 to 2001. Mov Disord 18(8):845-53

47. Hariz MI, Rehncrona S, Quinn NP, Speelman JD, Wensing C (2008) Multicenter study on deep brain stimulation in Parkinson's disease: an independent assessment of reported adverse events at 4 years. Mov Disord 23(3):416-21

48. Hass CJ, Waddell DE, Wolf SL, Juncos JL, Gregor RJ (2008) Gait initiation in older adults with postural instability. Clin Biomech (Bristol, Avon) 23(6):743-53

49. Hauptmann C, Roulet JC, Niederhauser JJ, Doll W, Kirlangic ME, Lysyansky B, Krachkovskyi V, Bhatti MA, Barnikol UB, Sasse L, Buhrle CP, Speckmann EJ, Gotz M, Sturm V, Freund HJ, Schnell U, Tass PA (2009) External trial deep brain stimulation device for the application of desynchronizing stimulation techniques. J Neural Eng 6(6):66003

50. Hemm S, Caire F, Coste J, Vassal F, Nuti C, Derost P, Ouchchane L, Sarry L, Durif F, Lemaire JJ (2008) Postoperative control in deep brain stimulation of the subthalamic region: the contact membership concept. Int J CARS DOI 10.1007/s11548-008-0152-6

51. Hemm S, Mennessier G, Vayssiere N, Cif L, El Fertit H, Coubes P (2005) Deep brain stimulation in movement disorders: stereotactic coregistration of two-dimensional electrical field modeling and magnetic resonance imaging. J Neurosurg 103(6):949-55

52. Herzog J, Hamel W, Wenzelburger R, Potter M, Pinsker MO, Bartussek J, Morsnowski A, Steigerwald F, Deuschl G, Volkmann J (2007) Kinematic analysis of thalamic versus subthalamic neurostimulation in postural and intention tremor. Brain 130(Pt 6):1608-25

53. Heuer GG, Zaghloul KA, Jaggi JL, Baltuch GH (2008) Use of an integrated platform system in the placement of deep brain stimulators. Neurosurgery 62(3 Suppl 1):245-7; discussion $247-8$

54. Hirabayashi H, Tengvar M, Hariz MI (2002) Stereotactic imaging of the pallidal target. Mov Disord 17 Suppl 3:S130-4 
55. Hoff JI, van der Meer V, van Hilten JJ (2004) Accuracy of objective ambulatory accelerometry in detecting motor complications in patients with Parkinson disease. Clin Neuropharmacol 27(2):53-7

56. Holloway KL, Gaede SE, Starr PA, Rosenow JM, Ramakrishnan V, Henderson JM (2005) Frameless stereotaxy using bone fiducial markers for deep brain stimulation. J Neurosurg 103(3):404-13

57. Hunsche S, Sauner D, Maarouf M, Poggenborg J, Lackner K, Sturm V, Treuer H (2009) Intraoperative X-ray detection and MRI-based quantification of brain shift effects subsequent to implantation of the first electrode in bilateral implantation of deep brain stimulation electrodes. Stereotact Funct Neurosurg 87(5):322-9

58. Johansson JD, Blomstedt P, Haj-Hosseini N, Bergenheim AT, Eriksson O, Wardell K (2009) Combined Diffuse Light Reflectance and Electrical Impedance Measurements as a Navigation Aid in Deep Brain Surgery. Stereotact Funct Neurosurg 87(2):105-113

59. Johansson JD, Fredriksson I, Wardell K, Eriksson O (2009) Simulation of reflected light intensity changes during navigation and radio-frequency lesioning in the brain. $\mathrm{J}$ Biomed Opt 14(4):044040

60. Journee HL, Postma AA, Staal MJ (2007) Intraoperative neurophysiological assessment of disabling symptoms in DBS surgery. Neurophysiol Clin 37(6):467-75

61. Kerr G, Morrison S, Silburn P (2008) Coupling between limb tremor and postural sway in Parkinson's disease. Mov Disord 23(3):386-94

62. Khan MF, Mewes K, Gross RE, Skrinjar O (2008) Assessment of brain shift related to deep brain stimulation surgery. Stereotact Funct Neurosurg 86(1):44-53

63. Koop MM, Andrzejewski A, Hill BC, Heit G, Bronte-Stewart HM (2006) Improvement in a quantitative measure of bradykinesia after microelectrode recording in patients with Parkinson's disease during deep brain stimulation surgery. Mov Disord 21(5):673-8

64. Krauss JK (2009) The Riechert/Mundiger stereotactic apparatus. In: Lozano AM, Gildenberg PL, Tasker RR (eds). Textbook of stereotactic and functional neurosurgery. Springer, Vol. 1, pp 488-494

65. Kumru H, Summerfield C, Valldeoriola F, Valls-Sole J (2004) Effects of subthalamic nucleus stimulation on characteristics of EMG activity underlying reaction time in Parkinson's disease. Mov Disord 19(1):94-100

66. Laitinen L, Johansson GG, Sipponen P (1966) Impedance and phase angle as a locating method in human stereotaxic surgery. J Neurosurg 25(6):628-33

67. Laitinen LV, Bergenheim AT, Hariz MI (1992) Leksell's posteroventral pallidotomy in the treatment of Parkinson's disease. J Neurosurg 76(1):53-61

68. Lane EL, Handley OJ, Rosser AE, Dunnett SB (2008) Potential cellular and regenerative approaches for the treatment of Parkinson's disease. Neuropsychiatr Dis Treat 4(5):835-45

69. Larson PS (2008) Technical alternatives in performiing deep brain stimulator implantation. In: Tarsy D, Vitek JL, Okun MS (eds). Current clinical neurology: Deep brain stimulation in neurological and phyciatric disordered. Humana Press, pp 12

70. Larson PS, Richardson RM, Starr PA, Martin AJ (2008) Magnetic resonance imaging of implanted deep brain stimulators: experience in a large series. Stereotact Funct Neurosurg 86(2):92-100

71. Larsson M, Steenbergen W, Strömberg T (2002) Influence of optical properties and fiber separation on laser doppler flowmetry. J Biomed Opt 7(2):236-43

72. Legros A, Diakonova N, Cif L, Hemm S, Vayssiere N, Coubes P, Beuter A (2004) Accelerometric measurement of involuntary movements during pallidal deep brain stimulation of patients with generalized dystonia. Brain Res Bull 64(4):363-9

73. Lemaire JJ, Coste J, Ouchchane L, Caire F, Nuti C, Derost P, Cristini V, Gabrillargues J, Hemm S, Durif F, Chazal J (2007) Brain mapping in stereotactic surgery: a brief 
overview from the probabilistic targeting to the patient-based anatomic mapping. Neuroimage 37 Suppl 1:S109-15

74. Leone M, Proietti Cecchini A, Franzini A, Broggi G, Cortelli P, Montagna P, May A, Juergens T, Cordella R, Carella F, Bussone G (2008) Lessons from 8 years' experience of hypothalamic stimulation in cluster headache. Cephalalgia 28(7):787-97; discussion 798

75. Li QH, Zamorano L, Pandya A, Perez R, Gong J, Diaz F (2002) The application accuracy of the NeuroMate robot--A quantitative comparison with frameless and framebased surgical localization systems. Comput Aided Surg 7(2):90-8

76. Liu Y, Postupna N, Falkenberg J, Anderson ME (2008) High frequency deep brain stimulation: what are the therapeutic mechanisms? Neurosci Biobehav Rev 32(3):34351

77. Lujan JL, Noecker AM, Butson CR, Cooper SE, Walter BL, Vitek JL, McIntyre CC (2009) Automated 3-dimensional brain atlas fitting to microelectrode recordings from deep brain stimulation surgeries. Stereotact Funct Neurosurg 87(4):229-40

78. Lunsford LD, Kondziolka D, Leksell D (2009) Leksell stereotactic apparatus. In: Lozano AM, Gildenberg PL, Tasker RR (eds). Textbook of stereotactic and functional neurosurgery. Springer, Vol. 1, pp 470-485

79. Machado A, Rezai AR, Kopell BH, Gross RE, Sharan AD, Benabid AL (2006) Deep brain stimulation for Parkinson's disease: Surgical technique and perioperative management. Mov Disord 21(S14):S247-S258

80. Maks CB, Butson CR, Walter BL, Vitek JL, McIntyre CC (2009) Deep brain stimulation activation volumes and their association with neurophysiological mapping and therapeutic outcomes. J Neurol Neurosurg Psychiatry 80(6):659-66

81. Martin AJ, Larson PS, Ostrem JL, Starr PA (2008) Interventional magnetic resonance guidance of deep brain stimulator implanatation for Parkinsons disease. Top Magn Reson Imaging 19(4):213-221

82. Mayberg HS, Lozano AM, Voon V, McNeely HE, Seminowicz D, Hamani C, Schwalb JM, Kennedy SH (2005) Deep brain stimulation for treatment-resistant depression. Neuron 45(5):651-60

83. McIntyre CC, Mori S, Sherman DL, Thakor NV, Vitek JL (2004) Electric field and stimulating influence generated by deep brain stimulation of the subthalamic nucleus. Clin Neurophysiol 115(3):589-95

84. McIntyre CC, Savasta M, Walter BL, Vitek JL (2004) How does deep brain stimulation work? Present understanding and future questions. J Clin Neurophysiol 21(1):40-50

85. Medtronic (2010) Medtronic DBS MRI Guidelines for Movement Disorders. http://professional.medtronic.com/interventions/deep-brain-stimulation/mri-guidelinesmovement/index.htm.Accessed 12 Jan 2010

86. Mikell CB, McKhann GM, Segal S, McGovern RA, Wallenstein MB, Moore H (2009) The hippocampus and nucleus accumbens as potential therapeutic targets for neurosurgical intervention in schizophrenia. Stereotact Funct Neurosurg 87(4):256-65

87. Miocinovic S, Noecker AM, Maks CB, Butson CR, McIntyre CC (2007) Cicerone: stereotactic neurophysiological recording and deep brain stimulation electrode placement software system. Acta Neurochir Suppl 97(Pt 2):561-7

88. Miyagi Y, Okamoto T, Morioka T, Tobimatsu S, Nakanishi Y, Aihara K, Hashiguchi K, Murakami N, Yoshida F, Samura K, Nagata S, Sasaki T (2009) Spectral analysis of field potential recordings by deep brain stimulation electrode for localization of subthalamic nucleus in patients with Parkinson's disease. Stereotact Funct Neurosurg 87(4):211-8

89. Morel A (2007) Stereotactic atlas of the human thalamus and basal ganglia. ed. Informa Healthcare USA Inc., 
90. Moringlane JR, Fuss G, Becker G (2005) Peroperative transcranial sonography for electrode placement into the targeted subthalamic nucleus of patients with Parkinson disease: technical note. Surg Neurol 63(1):66-9; discussion 69

91. Nowinski WL, Thirunavuukarasuu M, Benabid AL (2005) The Cerefy Clinical BrainAtlas: Enhanced edition with surgical planning and intraoperative support. CDROM

92. Owen SL, Heath J, Kringelbach ML, Stein JF, Aziz TZ (2007) Preoperative DTI and probabilistic tractography in an amputee with deep brain stimulation for lower limb stump pain. Br J Neurosurg 21(5):485-90

93. Palur RS, Berk C, Schulzer M, Honey CR (2002) A metaanalysis comparing the results of pallidotomy performed using microelectrode recording or macroelectrode stimulation. J Neurosurg 96(6):1058-62

94. Panescu D (2008) Emerging technologies. Implantable neurostimulation devices. IEEE Eng Med Biol Mag 27(5):100-5, 113

95. Papapetropoulos S, Gallo BV, Guevara A, Singer C, Mitsi G, Lyssikatos C, Jagid JR (2009) Objective tremor registration during DBS surgery for essential tremor. Clin Neurol Neurosurg 111(4):376-9

96. Papapetropoulos S, Jagid JR, Sengun C, Singer C, Gallo BV (2008) Objective monitoring of tremor and bradykinesia during DBS surgery for Parkinson disease. Neurology 70(15):1244-9

97. Patel NK, Khan S, Gill SS (2008) Comparison of atlas- and magnetic-resonanceimaging-based stereotactic targeting of the subthalamic nucleus in the surgical treatment of Parkinson's disease. Stereotact Funct Neurosurg 86(3):153-61

98. Pereira EA, Muthusamy KA, De Pennington N, Joint CA, Aziz TZ (2008) Deep brain stimulation of the pedunculopontine nucleus in Parkinson's disease. Preliminary experience at Oxford. Br J Neurosurg 22 Suppl 1:S41-4

99. Pinsker MO, Volkmann J, Falk D, Herzog J, Alfke K, Steigerwald F, Deuschl G, Mehdorn M (2008) Electrode implantation for deep brain stimulation in dystonia: a fast spin-echo inversion-recovery sequence technique for direct stereotactic targeting of the GPI. Zentralbl Neurochir 69(2):71-5

100. Pollo C, Villemure JG, Vingerhoets F, Ghika J, Maeder P, Meuli R (2004) Magnetic resonance artifact induced by the electrode Activa 3389: an in vitro and in vivo study. Acta Neurochir (Wien) 146(2):161-4

101. Qian Z, Sunder S, Yeqing G, Giller C, Liu H (2003) "Look-ahead distance" of a fiber probe used to assist neurosurgery: Phanton and Monte Carlo study. Optics express $11: 1844-1855$

102. Quinones-Hinojosa A, Ware ML, Sanai N, McDermott MW (2006) Assessment of image guided accuracy in a skull model: comparison of frameless stereotaxy techniques vs. frame-based localization. J Neurooncol 76(1):65-70

103. Rezai AR, Kopell BH, Gross RE, Vitek JL, Sharan AD, Limousin P, Benabid AL (2006) Deep brain stimulation for Parkinson's disease: surgical issues. Mov Disord 21 Suppl 14:S197-218

104. Schrader B, Hamel W, Weinert D, Mehdorn HM (2002) Documentation of electrode localization. Mov Disord 17 Suppl 3:S167-74

105. Sedrak M, Gorgulho A, De Salles AF, Frew A, Behnke E, Ishida W, Klochkov T, Malkasian D (2008) The role of modern imaging modalities on deep brain stimulation targeting for mental illness. Acta Neurochir Suppl 101:3-7

106. Starr PA, Christine CW, Theodosopoulos PV, Lindsey N, Byrd D, Mosley A, Marks WJ, Jr. (2002) Implantation of deep brain stimulators into the subthalamic nucleus: technical approach and magnetic resonance imaging-verified lead locations. J Neurosurg 97(2):370-87 
107. Starr PA, Martin AJ, Larson PS (2009) Implantation of deep brain stimulator electrodes using interventional MRI. Neurosurg Clin N Am 20(2):193-203

108. StJudeMedical (2010) Deep brain stimulation for parkinsons diesease. Accessed 12 Jan 2010

109. Sturman MM, Vaillancourt DE, Metman LV, Sierens DK, Bakay RA, Corcos DM (2007) Deep brain stimulation and medication for parkinsonian tremor during secondary tasks. Mov Disord 22(8):1157-63

110. Timmermann L, Braun M, Groiss S, Wojtecki L, Ostrowski S, Krause H, Pollok B, Sudmeyer M, Ploner M, Gross J, Maarouf M, Voges J, Sturm V, Schnitzler A (2008) Differential effects of levodopa and subthalamic nucleus deep brain stimulation on bradykinesia in Parkinson's disease. Mov Disord 23(2):218-27

111. Toda H, Sawamoto N, Hanakawa T, Saiki H, Matsumoto S, Okumura R, Ishikawa M, Fukuyama H, Hashimoto N (2009) A novel composite targeting method using high-field magnetic resonance imaging for subthalamic nucleus deep brain stimulation. J Neurosurg 111(4):737-45

112. Vasques X, Cif L, Hess O, Gavarini S, Mennessier G, Coubes P (2008) Stereotactic model of the electrical distribution within the internal globus pallidus during deep brain stimulation. J Comput Neurosci

113. Vayssiere N, Hemm S, Cif L, Picot MC, Diakonova N, El Fertit H, Frerebeau P, Coubes P (2002) Comparison of atlas- and magnetic resonance imaging-based stereotactic targeting of the globus pallidus internus in the performance of deep brain stimulation for treatment of dystonia. J Neurosurg 96(4):673-9

114. Vayssiere N, Hemm S, Zanca M, Picot MC, Bonafe A, Cif L, Frerebeau P, Coubes P (2000) Magnetic resonance imaging stereotactic target localization for deep brain stimulation in dystonic children. J Neurosurg 93(5):784-90

115. Voges J, Kiening K, Krauss JK, Nikkhah G, Vesper J (2009) [Neurosurgical standards in deep brain stimulation : consensus recommendations of the German Deep Brain Stimulation Association]. Nervenarzt 80(6):666-72

116. Vonck K, Boon P, Van Roost D (2007) Anatomical and physiological basis and mechanism of action of neurostimulation for epilepsy. Acta Neurochir Suppl 97(Pt 2):321-8

117. Walter U, Wolters A, Wittstock M, Benecke R, Schroeder HW, Muller JU (2009) Deep brain stimulation in dystonia: sonographic monitoring of electrode placement into the globus pallidus internus. Mov Disord 24(10):1538-41

118. Wårdell K, Blomstedt $\mathrm{P}$, Richter J, Antonsson J, Eriksson O, Zsigmond P, Bergenheim AT, Hariz MI (2007) Intracerebral microvascular measurements during deep brain stimulation implantation using laser Doppler perfusion monitoring. Stereotact Funct Neurosurg 85(6):279-86

119. Wårdell K, Johansson J, Richter J, Blomstedt P. (2009) Optical measurements for guidance during deep brain stimulation surgery. Medical Physics and Biomedical Engineering, World Congress, IFMBE Proceedings, pp 2

120. Witt K, Daniels C, Reiff J, Krack P, Volkmann J, Pinsker MO, Krause M, Tronnier V, Kloss M, Schnitzler A, Wojtecki L, Botzel K, Danek A, Hilker R, Sturm V, Kupsch A, Karner E, Deuschl G (2008) Neuropsychological and psychiatric changes after deep brain stimulation for Parkinson's disease: a randomised, multicentre study. Lancet Neurol 7(7):605-14

121. Yousif N, Bayford R, Bain PG, Liu X (2007) The peri-electrode space is a significant element of the electrode-brain interface in deep brain stimulation: a computational study. Brain Res Bull 74(5):361-8

122. Yousif N, Liu X (2007) Modeling the current distribution across the depth electrodebrain interface in deep brain stimulation. Expert Rev Med Devices 4(5):623-31 
123. Zrinzo L, Hariz M (2008) Impedance recording in functional neurosurgery. In: Gildenberg PL, Lozano AM, Tasker R (eds). Textbook of stereotactic and functional neurosurgery

124. Zylka W, Sabczynski J (1999) Effect of localization devices and registration methods on the accuracy of stereotactic frame systems predicted by the Gaussian approach. Comput Aided Surg 4(2):77-86 